\title{
Clinical Audit on Chronic Obstructive Pulmonary Disease (COPD) Management in Primary Care: A Quality Improvement Project from Hong Kong
}

\author{
Xiao Rui Catherine Chen' \\ Sau Nga Fu (D) ${ }^{2}$ \\ Wing Kit Leung ${ }^{3}$ \\ Sze Wing Catherine $\mathrm{Ng}^{4}$ \\ Wing Yan Wendy Kwan ${ }^{5}$ \\ Tseng Kwong Wong ${ }^{6}$ \\ Pang Fai Chan ${ }^{6}$ \\ Man Ying Michelle Wong ${ }^{5}$ \\ Wai Kit Welchie Ko ${ }^{4}$ \\ Jun Liang ${ }^{7}$ \\ Ming Tung Eric $\mathrm{Hui}^{3}$ \\ Yim Chu $\mathrm{Li}^{1}$ \\ Wan Luk ${ }^{2}$ \\ VK David Chao ${ }^{6}$

\begin{abstract}
'Department of Family Medicine and General Out Patient Clinics, Kowloon Central Cluster, Hospital Authority, Hong Kong; ${ }^{2}$ Department of Family Medicine and Primary Health Care, Kowloon West Cluster, Hospital Authority, Hong Kong; ${ }^{3}$ Department of Family Medicine, New Territories East Cluster, Hospital Authority, Hong Kong; ${ }^{4}$ Department of Family Medicine and Primary Health Care, Hong Kong West Cluster, Hospital Authority, Hong Kong; ${ }^{5}$ Department of Family Medicine and Primary Health Care, Hong Kong East Cluster, Hospital Authority, Hong Kong; ${ }^{6}$ Department of Family Medicine and Primary Health Care, Kowloon East Cluster, Hospital Authority, Hong Kong;

${ }^{7}$ Department of Family Medicine and Primary Health Care, New Territories West Cluster, Hospital Authority, Hong Kong
\end{abstract}

Correspondence: Xiao Rui Catherine Chen Department of Family Medicine and General Outpatient Clinics, Kowloon Central Cluster, Hospital Authority, Hong Kong Email uccxr758@ha.org.hk
Objective: To enhance the quality of COPD management in primary care via a two-phase clinical audit in Hong Kong.

Methods: COPD patients aged 40 or above and had attended any of the 73 public primary care clinics under the Hospital Authority of Hong Kong (HAHK) for follow up (FU) during the audit period were included. Performance of six evidence-based audit criteria on COPD care was reviewed in phase 1 from 1st April 2017 to 31st March 2018. Service gaps were identified and a series of quality improvement strategies were executed in the one-year implementation phase. The outcome of the service enhancement was assessed in phase 2 from 1st April 2019 to 31st March 2020. Student's $t$-test and the chi-square test were used to examine the statistically significant differences between the two phases.

Results: Totally 10,385 COPD cases were identified in phase 1, the majority were male $(87.7 \%)$ and the mean age was $75.3 \pm 9.9$ years. Among the 3102 active smokers, 1788 $(57.6 \%)$ were referred to receive the smoking cessation counselling and $1578(50.9 \%)$ actually attended it. A total of 4866 cases (46.9\%) received seasonal influenza vaccine (SIV) and 4227 cases (40.7\%) received pneumococcal vaccine (PCV). A total of 1983 patients $(19.1 \%)$ had spirometry test done before and 1327 patients $(12.8 \%)$ had history of hospital admission due to acute exacerbation of COPD (AECOPD). After the proactive implementation phase, performance on all criteria was significantly improved in phase 2 , with a marked increase in the SIV and PCV uptake rate and spirometry performance rate. Most importantly, a significant reduction in AECOPD rate leading to hospital admission had been achieved $(9.6 \%, P<0.00001)$.

Conclusion: COPD care at all public primary care clinics of HAHK had been significantly improved for all audit criteria via the systematic team approach, which, in turn, reduced the hospital admission rate and helped relieve the burden of the health care system.

Keywords: clinical audit, COPD, quality improvement, primary care

\section{Background}

Chronic obstructive pulmonary disease (COPD) is a progressive lung disease that has imposed a substantial economic and social burden to the health care system. ${ }^{1}$ According to The Global Burden of Disease Study, 251 million people were found to have COPD globally in 2016 and around 3.2 million people died from COPD in 2015. ${ }^{2}$ In Hong Kong (HK), the Population Health Survey 2014/15 reported that $0.5 \%$ of non-institutionalized persons aged 15 and above had doctor-diagnosed COPD. ${ }^{3}$ It accounted for over 30,000 episodes of inpatient discharges in 2016 and 1223 registered deaths in $2017 .^{4}$ 
As COPD is commonly encountered in primary care, family physicians have an essential role in taking comprehensive measures to improve the disease control and prevent its acute exacerbation. For example, evidence has clearly demonstrated that smoking cessation is the most effective intervention to slow down the disease progression of COPD. ${ }^{5}$ Proper diagnosis with a spirometry test and vaccination against influenza and pneumococcal infection have all been shown to reduce the disease burden. ${ }^{6-8}$ Despite all these evidences, loopholes existed in the management of COPD, particularly in primary care. For example, Kester et al found that only $5 \%$ of Canadian general practitioners requested a pulmonary function test when attending an individual with clear signs of COPD. ${ }^{9}$ It is also disappointing to note that the referral rate and attendance rate for smoking cessation counselling service among COPD smokers remained low ${ }^{10-11}$ and therefore their smoking cessation rate had been much poorer than those without COPD. Furthermore, the low take-up rate of seasonal influenza vaccine at $20-60 \%$ will render this vulnerable group of patients at a higher risk of developing chest infection during the winter surge. ${ }^{12-15}$ Acute exacerbation of COPD (AECOPD) would be inevitable if these preventive measures are not effectively implemented. Indeed, acute exacerbations have been proven to lead to accelerated decline in lung function, increased COPDrelated hospitalizations and augmented the health care utilization. ${ }^{16}$

In HK, about $20 \%$ of all COPD patients are managed at primary care clinics under the Hospital Authority of Hong Kong (HAHK). ${ }^{17}$ A pilot survey conducted in 2011 found that COPD care at both primary and secondary levels in HAHK needed to be improved. ${ }^{18}$ For example, spirometry was underused in the diagnosis and monitoring of patients with $\mathrm{COPD}^{19}$ and a suboptimal adherence to the accredited COPD management guideline was identified at five tertiary respiratory centers from 2013 to $2015{ }^{20}$ Inaccurate diagnosis due to lack of a popper lung function test, underutilization of long-acting bronchodilators and lack of an integrative care model were postulated to be the main issues to be tackled. ${ }^{21}$ To bridge this service gap, a COPD audit had been conducted across all primary care clinics of HAHK since 1st April 2017 with the purpose to plug these loopholes in COPD management and to enhance the quality of care. This study aimed to review the management of COPD cases from all primary care clinics of HAHK via a two phase clinical audit and to share out the improvement strategies. We believe that, by enhancing the COPD care via an aligned audit approach, its disease burden including COPD-related morbidity and mortality would be greatly reduced in the long run.

\section{Method}

\section{Study Design}

A two-phase clinical audit conducted at all 73 public primary care clinics of the HAHK.

\section{Setting Audit Criteria and Justification of Audit Standards}

The Quality Assurance (QA) subcommittee is a functional subcommittee under the leadership of the Coordination Committee of Family Medicine [COC (FM)] in HAHK. Its main mission is to promote evidence-based practice and to enhance the quality of care for all patients managed at General Outpatient Clinics (GOPCs) of HAHK. In late 2016, the QA subcommittee of COC (FM) agreed to conduct a COPD audit across all GOPCs to improve the COPD care. Clinical guidelines on COPD management published in recent 3 years were reviewed from the literature (https://pubmed.ncbi.nlm.nih.gov/). Members of the QA Subcommittee, who were specialist family physicians, designed six evidence-based audit criteria for COPD care after a through literature review. ${ }^{22,23}$ The standard of these audit criteria was benchmarked with recommendations from a similar audit done internationally. ${ }^{24}$ Feasibility in our own locality was also taken into consideration so that the target standard would be reachable. The audit criteria and performance standards are summarized in Table 1.

\section{The Audit Subjects}

COPD patients over 40 years old and had been regularly followed up (FU) at any of the 73 GOPCs of HAHK during the audit cycle were included. Locally, the HAHK has been responsible for managing HK's public hospitals since 1991. There are 7 Family Medicine Departments in 7 hospital clusters of HAHK, and totally 73 GOPCs are under its jurisdiction. The majority of patients attending the GOPCs for medical care are the elderly, the low income group and those with chronic diseases. The diagnosis of COPD was identified by the International Classification of Primary Care-2 code of "R79-Chronic bronchitis" or "R95-Chronic obstructive pulmonary disease" in the computerized Clinical Management System (CMS) of the HAHK. COPD patients managed in the hospital Specialist Outpatient Clinics (SOPCs) or certified 
Table I List of Audit Criteria and Performance Standard of the Study

\begin{tabular}{|c|c|c|}
\hline $\begin{array}{l}\text { Item } \\
\text { No. }\end{array}$ & Recommendations and Audit Criteria & Standard \\
\hline I & $\begin{array}{l}\text { Recommendations: All COPD patients should } \\
\text { receive a regular review for monitoring of } \\
\text { symptoms and discussion on management } \\
\text { plan. Criterion I: \% of COPD patients with } \\
\text { a pre-scheduled appointment in GOPC. }\end{array}$ & $85 \%$ \\
\hline 2 & $\begin{array}{l}\text { Recommendations: All COPD smokers should } \\
\text { be advised on smoking cessation and be } \\
\text { referred to Smoking Counselling and } \\
\text { Cessation Services (SCCS). } \\
\text { Criterion 2: COPD patients who are smokers: } \\
\text { a. \% of COPD patients referred to SCCS in } \\
\text { the audit phase; or } \\
\text { b. \% of COPD patients ever attended SCCS } \\
\text { in the audit phase. }\end{array}$ & $55 \%$ \\
\hline 3 & $\begin{array}{l}\text { Recommendations: All COPD patients should } \\
\text { receive seasonal influenza vaccine (SIV) annually } \\
\text { unless contraindicated. Criterion 3: \% of COPD } \\
\text { patients received SIV in the audit phase. }\end{array}$ & $50 \%$ \\
\hline 4 & $\begin{array}{l}\text { Recommendations: All COPD patients should } \\
\text { receive pneumococcal vaccine (PCV) unless } \\
\text { contraindicated. Criterion } 4: \% \text { of COPD } \\
\text { patients received PCV before. }\end{array}$ & $50 \%$ \\
\hline 5 & $\begin{array}{l}\text { Recommendations: Spirometry is } \\
\text { recommended for all COPD cases at diagnosis } \\
\text { or when the alternative diagnosis needs to be } \\
\text { ruled out, and to monitor the disease } \\
\text { progression. Criterion } 5: \% \text { of COPD patients } \\
\text { with spirometry test done before. }\end{array}$ & $50 \%$ \\
\hline 6 & $\begin{array}{l}\text { Recommendations: All efforts should be made } \\
\text { to reduce the acute exacerbation of COPD } \\
\text { (AECOPD). Criterion } 6: \% \text { of COPD patients } \\
\text { admitted to hospitals due to AECOPD during } \\
\text { the audit phase. }\end{array}$ & $<10 \%$ \\
\hline
\end{tabular}

dead during the audit cycle were excluded from the data analysis.

\section{The Audit Cycle}

Phase 1 was from 1st April 2017 to 31st March 2018, with deficiencies of care identified. To fill these service gaps, a oneyear implementation phase adopting a systemic approach to enhance the service delivery and outcome was carried out from 1st April 2018 to 31st March 2019. Phase 2 review was conducted from 1st April 2019 to 31st March 2020 to assess the effectiveness of these improvement strategies.

\section{First-Phase Data Collection and Analysis}

A COPD patient registry had been retrieved from the Clinical Data Analysis and Reporting System (CDARS) of HAHK by the Head Office Statistical Team. Total 12,003 COPD patients were identified during phase 1 . After case exclusion (454 cases were certified dead during phase 1 with an annual all-cause mortality rate of $3.8 \%$ and 1164 cases were regularly FU by respiratory specialists), 10,385 cases $(86.5 \%)$ were included into data analysis in phase 1 .

\section{Implementing Changes and Intervention}

The QA subcommittee of COC (FM) is composed of department heads and representatives from each Family Medicine Department in the 7 clusters of HAHK, all of whom are specialist family physicians. A cluster-based COPD audit working group led by the COC(FM) QA subcommittee member of each cluster was formed on $1 \mathrm{st}$ April 2017. Doctor and nurse subject officers were assigned subsequently. A structured team approach was adopted to set up strategies on administrative policy and workflow alignment. The COPD performance statistics were shared among clinic doctors and nurses at least annually. A regular working group meeting had been conducted at least half yearly accordingly to local service need. Closer collaboration with respiratory specialists was reinforced and mutual referral criteria had been delineated at cluster level.

At the practice level, a series of computer-based enhancement in the CMS was initiated to facilitate the COPD data capture. For example, a specifically designed "COPD module" was launched out in the CMS of all GOPCs in 2016. In this module, all COPD-related data including the epidemiological data and spirometry test results etc. were recorded. Moreover, a CMS reminder had been set up in almost all GOPCs to enhance the SCCS referral and vaccination upon patient's registration. Apart from the CMS enhancement, the workflow of COPD care in some GOPCs had also been revamped to meet the audit standard. For example, COPD cases would be referred to attend a nurse and an allied health team led assessment upon their routine FU, where a comprehensive range of services would be provided including nursing counselling on smoking cessation if current smoker and a course of pulmonary rehabilitation by allied health workers if indicated. Standard assessment including the Modified Medical Research Council (mMRC) dyspnea scale and COPD Assessment Test 
(CAT) score evaluation would also be conducted. During medical consultation, all doctors were recommended to order a spirometry test at diagnosis or when the alternative diagnosis needs to be ruled out and to monitor the disease progression. More office spirometry machines had been purchased to meet the increasing service demand on spirometry assessment. After exploring their hospital admission history, COPD patients were graded according to the definition of GOLD guideline and had been managed accordingly. ${ }^{22}$

At the clinic level, a policy on COPD risk factor screening was advocated, and a continuous monitoringand-feedback system with ongoing problem-solving was reinforced. Regular review on the progress of the audit was carried out where feedback regarding the deficiencies was tackled promptly. For example, the performance of each GOPC on COPD care would be reviewed at least biannually with loopholes identified. Meanwhile, the good practice from other GOPCs will be shared out for cross-learning purposes. At the doctor level, diagnosis and management of COPD and prevention of acute exacerbation based on the latest GOLD guideline had been promulgated to all frontline doctors to sharpen their skill set. All doctors were advised to manage COPD cases according to their severity as suggested by the grading system, and to make appropriate referrals if deemed necessary. Staff compliance to management guidelines was supervised by the doctor in charge of each individual clinic. At the patient level, a regular health talk had been organized by various ranks of staff to empower the patients on self-care and they were advised to seek medical care immediately should symptoms suggestive of AECOPD occur. All COPD smoker patients would be advised to receive the smoking cessation counselling service unless refusal to participate. The deficiencies in service provision and corresponding improvement strategies implemented are summarized in Table 2 .

\section{Second-Phase Data Collection and Analysis}

A total of 11,592 COPD patients were identified in phase 2 , among them 404 cases were certified dead (annual allcause mortality rate $3.5 \%$ ) and 1675 cases were found to have FU at SOPDs. In total, 9513 cases (82.1\%) were included into data analysis after case exclusion. The oneyear all cause mortality rate between the two phases was comparable $(\mathrm{P}=0.22)$.

\section{Determination of Variables}

The patients' demographic data were retrieved from the CMS of the HAHK. All data of the 6 audit criteria were retrieved from the CDARS of HAHK by the Head Office Statistical Team. An appointment is said to be prescheduled if the date of booking is at least 3 calendar days earlier than the date of appointment. A smoker is said to be referred to SCCS if he/she had an active appointment booked for SCCS. SIV and PCV vaccination rates were retrieved from the CMS immunization module. Criterion 6 on COPD patients admitted to hospitals due to AECOPD refers to the discharged episodes with principal diagnosis of COPD exacerbation during the reporting period. The ICD-9 diagnosis codes for acute exacerbations of COPD leading to hospital admission are listed in the Appendix.

\section{Statistical Methods}

All data were entered and analyzed using computer software SPSS version 21.0. The chi-square test was used for categorical variables and independent Student's $t$-tests were used for continuous variables to identify the differences of the measurements between the two phases. $P$ value of $<0.05$ was regarded as statistically significant.

\section{Results}

Table 3 summarizes the demographic characteristics of COPD patients included during the two phases. Their age, gender and smoking status were comparable. Around $88 \%$ of the COPD patients in both phases were male and the majority were elderly patients aged over 65 years old. Approximately $30 \%$ of COPD patients were chronic smokers. A total of 1144 cases $(11.0 \%)$ of all phase 1 patients were referred to respiratory specialists for continued care. Among the 9513 patients included in phase 2, 6088 patients were FU cases from phase 1, with a case overlapping rate of $64.0 \%$. At the end of phase 2 , 1057 cases $(11.1 \%)$ were referred to specialists for management . The SOPD referral rate had been comparable between the two phases $(P=0.83)$.

A comparison of the standards achieved in the two phases is summarized in Table 4. In the first phase, marked deficiencies were identified in almost all criteria. About one fifth of COPD patients (19.1\%) had performed spirometry before and 1327 cases (12.8\%) had at least one episode of hospital admission due to AECOPD. After 
Table 2 Summaries of Areas of Deficiencies and Strategies Implemented

\begin{tabular}{|c|c|}
\hline Areas of Deficiencies & Strategies Implemented \\
\hline \multicolumn{2}{|l|}{ Policy level } \\
\hline $\begin{array}{l}\text { Lack of a responsible team to coordinate the service } \\
\text { delivery centrally for COPD care }\end{array}$ & $\begin{array}{l}\text { Set up of COPD Audit Working Group in each cluster led by QA subcommittee member } \\
\text { of COC (FM) in HAHK. The members of the audit Working Group are from both doctors } \\
\text { and nurses, with audit subject officer or coordinator assigned. }\end{array}$ \\
\hline $\begin{array}{l}\text { Lack of regular review to monitor the service } \\
\text { performance }\end{array}$ & $\begin{array}{l}\text { Annual service review by Head Office Primary Health Care team on COPD care in all } \\
\text { clusters and share out data for FU action. }\end{array}$ \\
\hline Inadequate collaboration with SOPDs & $\begin{array}{l}\text { Collaborate with respiratory specialists in regional hospitals } \\
\text { Delineate clearer referral criteria of handling severe COPD cases and download } \\
\text { mechanism for stable COPD cases. }\end{array}$ \\
\hline
\end{tabular}

\section{Practice Level}

Lack of COPD data capture

"COPD Module" has been set up in the CMS since 2016 to facilitate the COPD-related data capture.

Lack of case registry

COPD case list of each cluster was retrieved by the HAHO statistical team and shared out with all $\mathrm{COC}(\mathrm{FM}) \mathrm{QA}$ subcom members.

Lack of guideline or protocol

Adopt standard guidelines and structural COPD assessment form or checklist.

Lack of aligned workflow

COPD management workflow was streamlined at cluster level. All doctors will book regular FU for COPD cases during routine consultation. COPD patients without a regular FU appointment were contacted by nursing staff to enquire about symptom control and a FU appointment would be offered if the patient had not received proper assessment in the recent one year.

Lack of office-based spirometry

More office spirometry machines had been purchased in local GOPCs to cater for the increasing service demand.

Lack of drugs for COPD care, such as LAMA/LABA Introduced LAMA/LABA to Family Medicine Specialist Clinic in some clusters since 2018.

\section{Staff}

Knowledge gap on COPD management

Poor compliance to COPD management guideline Improvement on education and training through online class, workshops and journal clubs.

All COPD patients were managed according to the grouping based on the latest GOLD guideline, compliance supervised by clinic doctor in charge.

Lack of communication and collaboration within the Sharing of workload among staff of all ranks in the team and closer collaboration with allied health team such as physiotherapist, occupational therapist and dietitian. CMS reminder had been set up by clerical staff upon patient's registration to remind them to receive vaccination.

Lack of feedback

Quarterly to biannually review on the progress at local clinic level, and deficiencies were tackled promptly.

\section{Patient}

Lack of awareness, knowledge and/or motivation on smoking cessation

Lack of self-empowerment programs on COPD care
Regular health talks and nurse counselling on smoking cessation were held at clinic level.

Closer collaboration with allied health workers to organize self-empowerment class and patient support groups on COPD care. proactive execution of the enhancement strategies during the implementation phase, significant improvement was observed with respect to all criteria in phase 2 . The most clinically important change was observed in the hospital admission rate due to AECOPD, reducing to $910(9.6 \%)$ in phase $2(P<0.00001)$. Further analysis on the frequencies 
Table 3 Demographic Characteristics of COPD Patients in the Two Phases

\begin{tabular}{|c|c|c|c|}
\hline & Phase I & Phase 2 & $P$ value \\
\hline $\begin{array}{l}\text { COPD cases included in } \\
\text { data analysis }(n)\end{array}$ & 10,385 & 9513 & - \\
\hline Gender & & & 0.53 \\
\hline Male & 9108 (87.7\%) & 837I (88.0\%) & \\
\hline Female & 1277 (I2.3\%) & II 42 (I2.0\%) & \\
\hline Age (years) & $75.3 \pm 9.9$ & $75.1 \pm 9.8$ & 0.92 \\
\hline$<40-49$ & 117 (1.1\%) & $92(1.0 \%)$ & 0.12 \\
\hline $50-64$ & 1559 (I5.0\%) & 1450 (I5.2\%) & \\
\hline $65-79$ & 503 I (48.4\%) & 4732 (49.7\%) & \\
\hline$\geq 80$ & 3678 (35.4\%) & 3239 (34.0\%) & \\
\hline Smoker & 3102 (29.9\%) & 3008 (31.6\%) & 0.08 \\
\hline $\begin{array}{l}\text { Case referred to } \\
\text { specialist care during the } \\
\text { audit period }\end{array}$ & II 44 (II.0\%) & I057 (II.I\%) & 0.83 \\
\hline
\end{tabular}

Notes: Data are shown as no. (\%) of cases or mean \pm standard deviation.

of hospital admissions due to AECOPD revealed that the reduction had been significant for all frequencies including being admitted once, twice, and three times or more between the two phases $(P<0.00001)$.

Further comparisons on the hospital admission rate due to AECOPD revealed that the reduction was only significant among the elderly age groups (from $14.1 \%$ in phase 1 to $10.5 \%$ in phase $2, P<0.00001$ ), whereas the improvement in the younger age group was not significant $(P=0.2)$ (Figure 1).

\section{Discussion}

Marked deficiencies were identified in various aspects of COPD management in the primary care setting in phase 1 . This is an expected albeit disappointing finding due to the service gaps at different levels such as knowledge set, skill set and tool set. The low smoking cessation service referral rate, suboptimal SIV and PCV uptake rate and underutilization of a spirometry test were the main service gaps. With the proactive implementation of all intensification strategies, COPD management at all public primary care clinics in HK had been enhanced, with performance in all six audit criteria being significantly improved and target audit standard achieved. The outcome criterion, AECOPD rate leading to hospital admission, was also markedly reduced in phase 2 .

It is of note that the overall headcounts of COPD patients under the care of HAHK had been decreasing over the years. One possible reason is that the diagnosis of COPD was much more accurate in phase 2 with a higher spirometry performance rate of $64.5 \%$ compared with phase $1(19.1 \%)$. This proper diagnostic process had

Table 4 Comparison of the Performance on the Audit Criteria Among COPD Patients Included in Phase I and Phase 2

\begin{tabular}{|c|c|c|c|c|}
\hline $\begin{array}{l}\text { Item } \\
\text { No. }\end{array}$ & Audit Criteria & $\begin{array}{l}\text { Phase I } \\
(n=10,385)\end{array}$ & $\begin{array}{l}\text { Phase } 2 \\
(n=95 \mid 3)\end{array}$ & $P$ value \\
\hline I & COPD patients with pre-scheduled appointments in GOPC & $8496(81.8 \%)$ & $8345(87.7 \%)$ & 0.00001 \\
\hline 2 & $\begin{array}{l}\text { COPD smokers } \\
\text { a. Have ever been referred to SCCS before } \\
\text { b. Have ever attended SCCS before }\end{array}$ & $\begin{array}{l}3102(29.9 \%) \\
1788(57.6 \%) \\
1578(50.9 \%)\end{array}$ & $\begin{array}{l}3008(31.6 \%) \\
1842(61.2 \%) \\
1653(55.0 \%)\end{array}$ & $\begin{array}{l}0.08 \\
0.004 \\
0.001\end{array}$ \\
\hline 3 & $\begin{array}{l}\text { COPD patients who have received SIV in the preceding year } \\
<65 \text { years old } \\
\geq 65 \text { years old }\end{array}$ & $\begin{array}{l}4866(46.9 \%) \\
324(6.7 \%) \\
4542(93.3 \%)\end{array}$ & $\begin{array}{l}5422(57.0 \%) \\
484(8.9 \%) \\
4938(91.1 \%)\end{array}$ & $\begin{array}{l}<0.00001 \\
0.00002\end{array}$ \\
\hline 4 & COPD patients with have received PCV & $4227(40.7 \%)$ & $5665(59.6 \%)$ & $<0.00001$ \\
\hline 5 & COPD patients with spirometry test done & $1983(19.1 \%)$ & $6140(64.5 \%)$ & $<0.00001$ \\
\hline 6 & $\begin{array}{l}\text { COPD patients admitted to hospitals due to acute exacerbation (AECOPD) } \\
\text { Frequencies of hospital admission } \\
\text { Nil } \\
\text { Once } \\
\text { Twice } \\
\geq 3 \text { times }\end{array}$ & $\begin{array}{l}\text { I } 327(12.8 \%) \\
9058(87.2 \%) \\
824(7.9 \%) \\
283(2.7 \%) \\
220(2.1 \%)\end{array}$ & $\begin{array}{l}910(9.6 \%) \\
8603(90.4 \%) \\
583(6.1 \%) \\
187(2.0 \%) \\
140(1.5 \%)\end{array}$ & $\begin{array}{l}<0.00001 \\
<0.00001\end{array}$ \\
\hline
\end{tabular}

Note: Data are shown as no. (\%). 


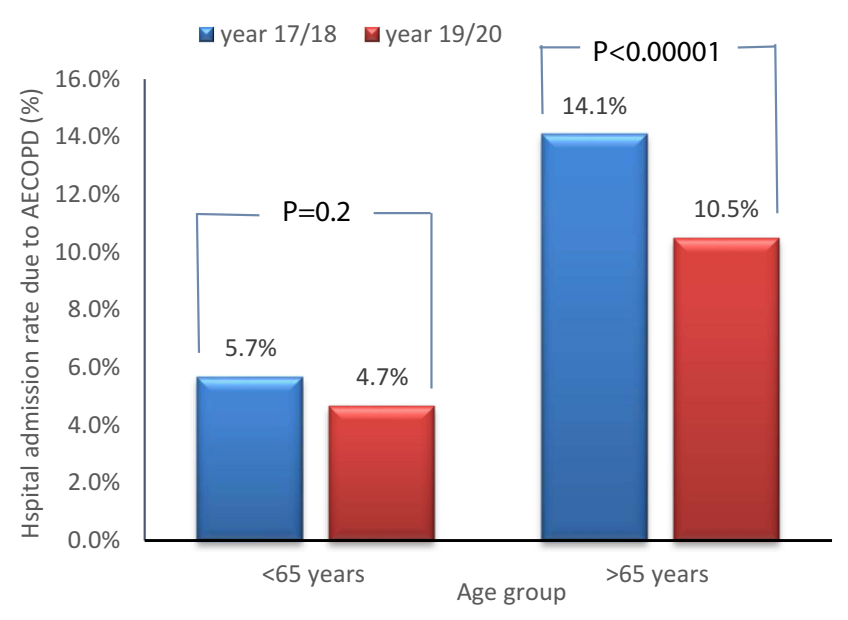

Figure I Comparison of hospital admission rate due to AECOPD among different age groups between the two phases.

prevented the over-diagnosis of COPD exited in phase 1 due to a lack of spirometry. Another possibility is that, in view of the comparable annual overall mortality rate and SOPD referral rate between the two phases, the reduction in the total case number of COPD could be due to the decreased prevalence of COPD in HK although the exact data are still lacking. Indeed, an overview on the prevalence and incidence of chronic respiratory disease published early this year showed that the incidence rate of COPD decreased in all age groups from 1990 to 2017 globally, except for elderly patients older than 80 years. ${ }^{25}$ This reduced prevalence could partially be explained by the fact that the prevalence of daily cigarette smokers of HK dropped to $10.0 \%$ in 2017 , which is the lowest rate recorded since 1982 according to the Thematic Household Survey released by Census and Statistics Department of $\mathrm{HK}^{26}$

Smoking cessation is the most effective intervention in stopping the progression of COPD so as to increase its survival. A more favorable attitude from the attending doctor was also proved to be associated with higher rates of smoking cessation behavior from the smoker patients. ${ }^{27}$ This is why smoking cessation should be the top priority in the treatment of COPD for all primary care doctors. Disappointingly, compliance with guideline recommendations is always an issue, with only about half of COPD smokers being referred and even fewer actually attended the SCCS in phase 1. Indeed, low smoking cessation service referral has been identified among all smokers throughout the world. For example, only a third of the smokers in the United States tried to quit by using counselling and medication in $2015,{ }^{28}$ and fewer than $5 \%$ of smokers attended a smoking cessation service in the United Kingdom every year. ${ }^{29}$ In Hong Kong, only $2.4 \%$ of smokers used smoking cessation service in $2018 .^{30}$ This low referral rate might be explained by evidence suggesting that COPD smokers are usually poorly motivated to quit smoking in general. ${ }^{10}$ Another possibility is the physician-related factor. Although all primary care doctors are recommended to provide smoking cessation advice to smokers during their routine consultation, some physicians failed to do so partly due to lack of cessation-specific knowledge or skills and partly due to insufficient consultation time. ${ }^{31}$ This is particularly challenging to doctors working at public primary care clinics of HK where the average consultation time for each patient was only about 7 minutes. To sharpen their counselling skill, a series of training programs on motivational interview had been organized centrally by the Head Office of HKHA and the Mayo Clinic Model on smoking cessation counselling has been provided to all staff working at the SCCS clinic in HKHA. Furthermore, as smokers tend to default their appointment due to various reasons, the SCCS counselling was delivered right on the spot once referred, thus resulting in a significantly lower default rate. With all these efforts, the situation in phase 2 had been improved with the target standard achieved. All doctors will continue to proactively motivate COPD smokers to attend the SCCS so that a higher quit rate could be achieved.

Concerning the uptake rate of SIV and PCV, although our performance had significantly improved during the audit cycle, only more than half of COPD patients were vaccinated against SIV (57.0\%\%) and PCV (59.6\%) in phase 2. This is consistent with findings in the literature that influenza vaccination coverage rates among COPD patients remain low in many countries. ${ }^{13,14}$ Although the benefits of influenza vaccination far outweigh its risk for COPD care, some patients still refuse vaccinations due to concerns over the adverse reactions. Another potential reason is the cost. Locally, the HK Government has subsidized the elderly aged over 65 years to receive the SIV and PCV for free for more than 10 years already, whereas those relative younger ( $<65$ years) have to receive the shot using their own money. This was reflected by the breakdown figures of SIV coverage among those under age 65, which was alarmingly low $(6.7 \%$ in phase 1 and $8.9 \%$ in phase 2) compared with the elderly patients. Given the widely established evidence on the long-term benefits of SIV on COPD care, such as reduced number of exacerbations, hospitalizations and all-cause mortalities, ${ }^{7}$ we would 
like to propose that HK government should launch out free SIV to COPD patients of all ages to reduce their morbidity and mortality.

It is alarming to find that only $19.1 \%$ COPD patients had a spirometry test before in phase 1 . This was consistent with local studies done in 2013 showing that spirometry had been underused in general but especially by family physicians in the management of COPD patients, with only $18.3 \%$ of patients having spirometry done during diagnostic workup. ${ }^{19}$ The reasons accounting for this poor performance rate are multifactorial. At the doctors' level, some doctors often make the diagnosis of COPD based on clinical features alone. At the clinic level, a spirometry service was previously only available in a hospital setting. Therefore, suspected COPD patients had to be referred to a Respiratory Specialist Clinic to perform the lung function tests where the waiting time ranged from months to two years under HAHK. To plug this loophole, a series of education talks on the proper diagnosis and management of COPD, emphasizing the importance of a spirometry test, were delivered to all doctors. Furthermore, some selected GOPCs were equipped with a spirometry machine during the implementation phase so that the spirometry test could be conveniently performed locally within 2-4 weeks. In addition, at least 1-2 designated nurses from these GOPCs had been specially trained on how to perform the spirometry correctly based on the aligned standard. With such facilitations both on the skill set and tool set, tremendous improvement was observed for this criterion in phase 2 (64.5\%, $P<0.00001)$.

The last criterion on the hospital admission rate due to AECOPD is the single most important outcome criterion of this audit. Mild to moderate AECOPD successfully managed at the outpatient setting was not included. Approximately 1 in 8 of COPD patients $(12.8 \%)$ had been admitted to hospital due to AECOPD in phase 1. This rate was lower than those reported in the literature, which showed around $20 \%$ of COPD patients had experienced severe acute exacerbations leading to hospital admission annually. ${ }^{32,33}$ This discrepancy might be explained by different severities of COPD patients managed at different settings. For example, majority of COPD cases managed in primary care clinics belong to the mild grade (Group A and B) according to the GOLD guideline. Indeed, local data from Kowloon Center Cluster of HAHK have confirmed that only about $10 \%$ of COPD cases FU in primary care clinics belonged to Group $\mathrm{C}$ and D. ${ }^{34}$ In order to further decrease the burden of hospital admissions, prevention and prompt treatment of exacerbations are the crux in COPD care. With such mindset, a series of service enhancement strategies were executed. Firstly, early identification of COPD patients by spirometry and proper grading according to the GOLD guideline were done as mentioned above. Secondly, all COPD cases were managed in a stepwise approach suggested by the GOLD guideline, hence providing the right level of care to the right patients. For more severe Group C/D patients who warrant advanced care, a timely referral to the Respiratory Specialists would be initiated. Lastly, a rescue pack has been dispatched to high-risk COPD patients in some clinics and a more frequent pulmonary rehabilitation service has been offered to unstable COPD patients, hence preventing the hospital admission due to AECOPD. With all these proactive interventions and efforts, the AECOPD rate leading to hospital admission was significantly reduced to $9.6 \%$ in phase 2. In addition, the reduction was significant for COPD patients admitted to hospital at all frequencies, proving that our strategies were effective for COPD patients of different severities.

To our knowledge, this study is one of the biggest clinical audits on COPD management ever conducted internationally. It has provided crucial information on COPD care in the primary care setting ranging from preventive measures, diagnostic process and outcome assessment. Its wide coverage (all 73 public primary care clinics in HAHK) and large sample size (around 10,000 cases in both phase 1 and phase 2) have significantly increased the statistical power of the study. All audit criteria were based on objective measurements with data being retrieved from the computer system of HAHK, therefore minimizing the confounding effect due to recall basis or data entry error. With that being said, this study has several limitations. Firstly, the study was carried out in public primary care clinics of HAHK, therefore the results may not be applicable to the secondary care setting or the private sector. Nevertheless, since COPD cases from all 73 GOPCs of HAHK had participated in the clinical audit, these data should realistically represent the COPD care in public primary care settings and provide groundwork for future service enhancement. Secondly, due to the time constraint, this clinical audit mainly focused on the process criteria and some short-term outcome aspects of COPD management. Long-term outcomes such as lung function improvement or COPD-related mortality rate were not analyzed. In addition, other important process indicators such as assessment of inhaler technique, referral to pulmonary 
rehabilitation service and patient self-empowerment program etc. had not been included. This gap will need to be filled as evidence has revealed that early pulmonary rehabilitation, inhaler technique education and patient selfempowerment all significantly reduced the acute exacerbation rate of COPD. ${ }^{35,36}$ Subsequent studies focusing on these aspects may help provide a more thorough picture of COPD management.

\section{Conclusion}

COPD management at all primary care clinics of HAHK had been significantly enhanced during the past three years. Via a team approach with streamlined governance and structure as well as proactive staff engagement, marked improvement had been achieved in all audit criteria for COPD management in HK. The significant reduction in hospital admission rate due to AECOPD will help relieve the burden to respiratory specialists and hospitals in the long run.

\section{Article Summary}

Strengths and limitations of this study:

- This study is one of the biggest clinical audits on COPD management ever conducted internationally. It has provided crucial information on COPD care in the primary care setting ranging from preventive measures, diagnostic process and outcome assessment. It has covered all 73 public primary care clinics in HAHK and the sample size was large, including more than 10,000 cases in both phase 1 and phase 2 .

- All audit criteria were based on objective assessment parameters with data being retrieved from the computer system of HAHK, therefore minimizing the confounding effect due to recall basis or data entry error.

- However, as the study was carried out in public primary care clinics of HAHK, the results may not be generalized to the other settings like the private sector, secondary care setting or other countries or area.

- As only process criteria and short-term outcome aspects of COPD management were audited in this report, long-term outcomes such as lung function improvement or COPD-related mortality rate were not compared. In addition, other process indicators such as assessment on inhaler technique and referral to pulmonary rehabilitation etc. were not included. Subsequent studies focusing on these aspects may help provide a more thorough picture of COPD management.

\section{Abbreviations}

AECOPD, acute exacerbation of chronic obstructive pulmonary disease; CAT, COPD assessment test; CDARS, Clinical Data Analysis and Reporting System; CMS, Clinical Management System; COPD, chronic obstructive pulmonary disease; FU, follow up; GOLD guideline, Global Initiative for Obstructive Lung Disease guideline; GOPCs, General Outpatient Clinics; HAHK, Hospital Authority of Hong Kong; HK, Hong Kong; LABA, long acting beta-agonist; LAMA, long acting anti-muscarinic antagonist; mMRC, Modified Medical Research Council; PCV, pneumococcal vaccine; QA subcommittee of COC (FM); Quality Assurance subcommittee of the Coordination Committee in Family Medicine; SCCS, smoking counselling and cessation service; SIV, seasonal influenza vaccine; SOPCs, Specialist Outpatient Clinics.

\section{Data Sharing Statement}

The datasets used in the current study were compiled by the hospital statistical team from the head office of HAHK and are used as internal reference only. They would be available from the corresponding author on reasonable request after being approved by headquarters of HAHK. Extra data is available by emailing Dr Catherine Chen at uccxr758@ha.org.hk

\section{Ethics and Consent to Participate or Publish}

According to recommendations from the local Research Ethics Committee of the HAHK, ethical approval is not required for clinical audit. As only the medical records of the recruited cases were reviewed and their clinical management was not affected, neither verbal nor written consent to participate in the study or to publish the study is required.

\section{Acknowledgment}

We would like to thank all medical staff in 73 GOPCs from the seven clusters of the HAHK, namely Hong Kong Easter Cluster, Hong Kong West Cluster, Kowloon East Cluster, Kowloon Central Cluster, Kowloon West Cluster, New Territory East Cluster and New Territory West Cluster, for their professional service. We would also like to thank all members of the COC (FM) QA Subcommittee for their leadership in setting up the audit criteria across all GOPCs in HAHK. The great support from the Primary Health Care team of the Head Office of HAHO, particularly Ms Ruby Kwok, Dr Tony Ha and Dr Libby Li, is also highly valued. Our gratitude also goes to Head Office Statistical Team 
of HAHK and Ms Katherine Chan, Statistical Officer I of Queen Elizabeth Hospital of Kowloon Central Cluster for their tremendous support in retrieving the COPD data from the CMS and CDARS system of the HAHK.

\section{Author Contributions}

This study has not been presented, published or posted online before. All authors made a significant contribution to the work reported, whether that is in the conception, study design, execution, acquisition of data, analysis and interpretations, or in all these areas; took part in drafting, revising or critically reviewing the article; gave final approval of the version to be published; have agreed on the journal to which the article has been submitted; and agree to be accountable for all aspects of the work. Dr Catherine Chen contributed to the analysis and interpretation of the data, drafting the manuscript and critical revision for important intellectual content.

\section{Funding}

This research project was not funded by any agency in the public, commercial, or not-for- profit sectors.

\section{Disclosure}

All authors have declared no conflicts of interest.

\section{References}

1. Rabe KF, Watz H. Chronic obstructive pulmonary disease. Lancet. 2017;389(10082):1931-1940. doi:10.1016/S0140-6736(17)31222-9

2. World Health Organization. Chronic Obstructive Pulmonary Disease (COPD). Geneva; 2016.

3. Department of Health. Population Health Survey 2014/15. Hong Kong SAR:Department of Health; 2015.

4. Hospital Authority, Department of Health and Census and Statistics Department. Inpatient Statistics 2016. Hong Kong SAR:Hospital Authority, Department of Health and Census and Statistics Department; 2016.

5. Anthonisen NR, Connett JE, Kiley JP, et al. Effects of smoking intervention and the use of an inhaled anticholinergic bronchodilator on the rate of decline of FEV1. The Lung Health Study. JAMA. 1994;272(19):1497-1505. doi:10.1001/jama.1994.03520190043033

6. Soriano JB, Zielinski J, Price D. Screening for and early detection of chronic obstructive pulmonary disease. Lancet. 2009;374:721-732. doi:10.1016/S0140-6736(09)61290-3

7. Bekkat-Berkani R, Wilkinson T, Buchy P, et al. Seasonal influenza vaccination in patients with COPD: a systematic literature review. BMC Pulm Med. 2017;17(1):79. doi:10.1186/s12890-017-0420-8

8. Walters JA, Tang JN, Poole P, Wood-Baker R. Pneumococcal vaccines for preventing pneumonia in chronic obstructive pulmonary disease. Cochrane Database Syst Rev. 2017;1(1):CD001390.

9. Kester S, Chapman KR. Physician perceptions and management of COPD. Chest. 1993;104:254-258. doi:10.1378/chest.104.1.254

10. Jiménez-Ruiz CA, Masa F, Miravitlles M, et al. Smoking characteristics: differences in attitudes and dependence between healthy smokers and smokers with COPD. Chest. 2001;119(5):1365-1370. doi:10.1378/chest.119.5.1365
11. Miriam J, Evelien ES, Frans H. Smoking cessation strategies in patients with COPD. Eur Respir J. 2013;41:727-734. doi:10.1183/ 09031936.00014012

12. Ciblak MA, Platformu G. Influenza vaccination in Turkey: prevalence of risk groups, current vaccination status, factors influencing vaccine uptake and steps taken to increase vaccination rate. Vaccine. 2013;31:518-523. doi:10.1016/j.vaccine.2012.11.022

13. European Centre for disease prevention and control (ECDC). Seasonal influenza vaccination in Europe - overview of vaccination recommendations and coverage rates in the EU member states for the 2012-2013 influenza season, technical report. Eur Centre Dis Prev Control. 2015.

14. Centers for disease control and prevention (CDC). Flu vaccination coverage, United States, 2014-15 influenza season; 2016. Available from: http://www.cdc.gov/flu/fluvaxview/coverage-1415estimates. htm. Accessed 31 January 2019.

15. Chronic obstructive pulmonary disease. MOH Singapore clinical practice guidelines $2 / 2017$.

16. Qureshi H, Sharafkhaneh A, Hanania NA. Chronic obstructive pulmonary disease exacerbations: latest evidence and clinical implications. Ther Adv Chronic Dis. 2014;5(5):212-227. doi:10.11 $77 / 2040622314532862$

17. Statistics and Workforce Planning Department. Strategy and Planning Division. Hospital Authority. Hospital Authority Statistical Report 2017-2018. HKSAR: Hospital Authority; 2018.

18. Yu WC, Tai EL, Fu SN, et al. Treatment of patients with chronic obstructive pulmonary disease as practised in a defined Hong Kong community: a cross-sectional pilot survey. Hong Kong Med J. 2011;17(4):306-314.

19. Yu WC, Fu SN, Tai EL, et al. Spirometry is underused in the diagnosis and monitoring of patients with chronic obstructive pulmonary disease (COPD). Int $J$ Chron Obstruct Pulmon Dis. 2013;8:389-395. doi:10.2147/COPD.S48659

20. Chan KP, Ko FW, Chan HS, et al. Adherence to a COPD treatment guideline among patients in Hong Kong. Int $J$ Chron Obstruct Pulmon Dis. 2017;12:3371-3379. doi:10.2147/COPD. S147070

21. Chan HS, Ko FWS, Chan JWM, et al. Comorbidities, mortality, and management of chronic obstructive pulmonary disease patients who required admissions to public hospitals in Hong Kong - computerized data collection and analysis. Int J Chron Obstruct Pulmon Dis. 2018;13:1913-1925. doi:10.2147/COPD.S163659

22. Global strategy for the diagnosis, management and prevention of chronic obstructive pulmonary disease (2017 report). Available from: https://goldcopd.org/wp-content/uploads/2016/12/wms-GOLD -2017-Pocket-Guide.pdf. Accessed June 8, 2021.

23. Chronic obstructive pulmonary disease in over 16s: diagnosis and management. National Institute for Health and Care Excellence Guideline (NG115), published 05 December 2018.

24. National Asthma and Chronic Obstructive Pulmonary Disease Audit Programme (NACAP). Wales primary care clinical audit 2020 Clinical audit report Published March 2021. 2021

25. Xie M, Liu X, Cao X, et al. Trends in prevalence and incidence of chronic respiratory diseases from 1990 to 2017. Respir Res. 2020;21:49. doi:10.1186/s12931-020-1291-8

26. Thematic Household Survey Report No. 64. Census and Statistics Department, Hong Kong Special Administrative Region; 2018. Available from: https://www.statistics.gov.hk/pub/ B11302642018XXXXB0100.pdf. Accessed June 8, 2021.

27. Meredith LS, Yano EM, Hickey SC, Sherman SE. Primary care provider attitudes are associated with smoking cessation counseling and referral. Med Care. 2005;43(9):929-934. doi:10.1097/01. mlr.0000173566.01877.ac

28. Babb S, Malarcher A, Schauer G, Asman KAJ. Quitting smoking among adults-United States, 2000-2015. Morb Mortal Wkly Rep. 2017;65:1457-1464. doi:10.15585/mmwr.mm6552a1 
29. Health and Social Care Information Centre. Statistics on NHS Stop Smoking Services in England: April 2014 to March 2015. Leeds, UK Health and Social Care Information Centre; 2015.

30. Census and Statistics Department. Thematic Household Survey, Report No. 64: Pattern of Smoking. Hong Kong SAR: Hong Kong SAR Government; 2018.

31. Van Eerd EAM, Bech Risør M, Spigt M, et al. Why do physicians lack engagement with smoking cessation treatment in their COPD patients? A multinational qualitative study. NPJ Prim Care Respir Med. 2017;27(1):41. doi:10.1038/s41533-017-0038-6

32. Mittmann N, Kuramoto L, Seung SJ, et al. The cost of moderate and severe COPD exacerbations to the Canadian healthcare system. Respir Med. 2008;102(3):413-421. doi:10.1016/j.rmed.2007.10.010

33. Lim S, Lam DC, Muttalif AR, et al. Impact of chronic obstructive pulmonary disease (COPD) in the Asia-Pacific region: the EPIC Asia population-based survey. Asia Pac Fam Med. 2015;14:4. doi:10.1186/s12930-015-0020-9
34. Chen XRC, Leung SH, Li YC. Chronic Obstructive Pulmonary Disease (COPD) management in the community: how could primary care team contribute? BMC Fam Pract. BMC Family Practice. 2020;21(1):184. doi:10.1186/s12875-020-01256-0

35. Maricoto T, Monteiro L, Gama JMR, et al. Inhaler Technique Education and Exacerbation Risk in Older Adults with Asthma or Chronic Obstructive Pulmonary Disease: a Meta-Analysis. J Am Geriatr Soc. 2019;67(1):57-66. doi:10.1111/jgs.15602

36. Wedzicha JA. COPD exacerbations: defining their cause and prevention. The lancet. 2007;310(9589):786-796. doi:10.1016/ S0140-6736(07)61382-8

\section{Publish your work in this journal}

The International Journal of COPD is an international, peer-reviewed journal of therapeutics and pharmacology focusing on concise rapid reporting of clinical studies and reviews in COPD. Special focus is given to the pathophysiological processes underlying the disease, intervention programs, patient focused education, and self management protocols. This journal is indexed on PubMed Central, MedLine and CAS. The manuscript management system is completely online and includes a very quick and fair peer-review system, which is all easy to use. Visit http://www.dovepress.com/testimonials.php to read real quotes from published authors 